\title{
Harm reduction over morals to reduce smoking deaths
}

$\mathrm{C}$ anadian tobacco-control policies could save tens of thousands of lives this century if regulators applied ethical public health principles such as harm reduction instead of taking a moralistic approach to tobacco consumption, says a leading opponent of Big Tobacco.

"We have a very long history of beating the cigarette companies," says David Sweanor, an adjunct professor of law at the University of Ottawa. "In my experience, it's not hard to beat cigarette companies. It's hard to get our colleagues to accept what you should do in terms of a pragmatic strategy rather than an absolutist one."

Sweanor, who spoke recently at the National Health Law Conference in Ottawa, argues that tobacco-control efforts have demonized not only the tobacco companies but also smokers, distorting the policy debate as a result. Although research has long linked cancer to inhaling smoke from cigarettes, rather than nicotine itself, that evidence has not effectively influenced regulatory approaches, he contends.

As a result, in the more than 30 years that Sweanor has been involved in global tobacco litigation against tobacco companies, including as legal counsel for the Non-Smokers Rights Association, smoking has remained the leading cause of preventable death in Canada. Despite major reductions in smoking rates, smoking will cause a million deaths among Canadians by the end of the century, he says, based on current trends and consumption.

"I'm not pleased with what we've accomplished," says Sweanor, whom the Pan American Health Organization has named one of its Public Health Heroes. "Certainly, playing with affordability has been far and away the most important thing we've done. But I think any action we look at has to be seen against what was achievable."

Sweanor's arguments highlight the tension in the tobacco-control community and among public health officials

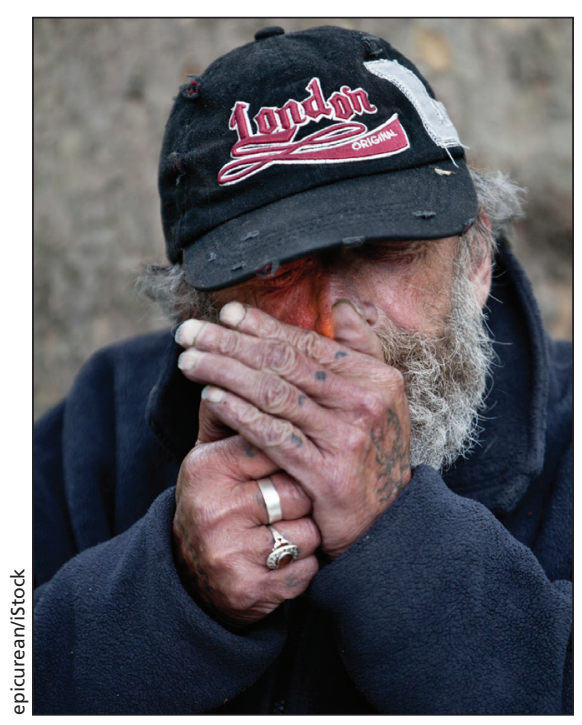

Increasing taxes on cigarettes reduces smoking rates but can cause financial hardship for some low-income populations, such as the homeless and those with addictions.

over the issue of e-cigarettes, vaping and other nicotine-replacement products. Some smoking cessation proponents believe insufficient evidence exists that e-cigarettes will help people quit smoking, despite the fact that e-cigarettes either vastly reduce or in some cases eliminate the nitrosamines that cause cancer. Those who argue for bans on e-cigarettes are afraid they will become "gateway" devices to tobacco, particularly for young users.

Others, including Sweanor, point to examples from countries such as Sweden as the reason Canada should take the same harm-reduction approach to reduce smoking that public health officials apply to injection drug use (safe injection sites) and sexual health, (promoting and distributing condoms).

In Sweden, the use of snus, a smokeless tobacco product that people (primarily men) rub on their gums, is driving down the use of cigarettes. There are far fewer tobacco-related deaths among men in Sweden than in other European countries, Sweanor pointed out in a recent article he coauthored in the New England Journal of Medicine.
"We're just telling people 'Thou Shalt Not' and it doesn't make any public health sense. We could virtually eliminate the risk by getting rid of the smoke," he says.

By ignoring the public health dictate of reducing the risk for people who continue to smoke, "we've really stymied our progress," Sweanor says. Increasing the taxes on cigarettes persuaded many people to quit smoking, but "the people who couldn't or wouldn't were put at an economic disadvantage." For lowincome people who smoke, often those with mental illnesses or genetic predispositions who self-medicate with nicotine, the cost of cigarettes combined with their addictions reduces their ability to buy healthy food, he says.

True harm reduction could even include such measures as subsidizing e-cigarettes for homeless people, suggests Ronald Labonté, the Canada Research Chair in Globalization and Health Equity at the University of Ottawa, who spoke at the same conference as Sweanor.

Policymakers and legislators have focused on the moralistic goal of achieving a tobacco-free world rather than taking concrete steps to reduce death and disease, says Sweanor. That approach has resulted in attempts to ban e-cigarettes or regulate them like medicine. At the very least, Canada should launch a public health campaign to educate smokers about the reduced risk of vaping or using other nicotinereplacement products over smoking, he argues.

Ideally, effective nicotine-replacement products should be widely available without a prescription, e-cigarettes and oral tobacco products should be available behind the counter at pharmacies and cost less than cigarettes, and cigarettes would be out of sight or not sold because the market for them would disappear, he says. - Laura Eggertson, Ottawa, Ont.

CMAJ 2016. DOI:10.1503/cmaj.109-5203 